\title{
Tax distortions to the choice of organizational form
}

\author{
Roger H. Gordon*, Jeffrey K. MacKie-Mason \\ Department of Economics, University of Michigan, Ann Arbor, MI 48109-1220, \\ USA and NBER
}

Received November 1992, revised version received December 1993

\begin{abstract}
Income from corporate and noncorporate firms is treated very differently under the tax law. In theory, given existing tax law, the noncorporate sector should consist of very profitable firms owned by low-tax-bracket investors and firms with tax losses owned by high-tax-bracket investors. But the degree to which firms change their form of organization in response to taxes, and the resulting excess burden, depends as well on nontax factors. Given the role of taxes, we estimate what size the nontax advantage to incorporating must take in each industry so that the forecasted choices for organizational form, aggregated over investors in different tax brackets, are consistent with the aggregate evidence. While the estimated nontax costs are large in some industries, noncorporate activity tends to be concentrated where the costs are small, leading to little excess burden from the tax distortion to organizational form.
\end{abstract}

JEL Classification: $\mathrm{H} 25 ; \mathrm{D} 23 ; \mathrm{G} 32$

\section{Introduction}

Income from an incorporated firm is treated very differently than income from an unincorporated firm under U.S. tax law. Corporate income is fully taxable under the corporate income tax, and partially taxable under the personal income tax, whereas noncorporate income faces only the personal

* Corresponding author. 
income tax. Given the progressivity of personal income tax rates, the relative tax treatment of corporate vs. noncorporate income depends in large part on the identity of the owners. To what degree does the distribution of firms across forms of organization respond to these differences in tax treatment? What are the efficiency costs that result from the tax-induced changes in the forms of organization chosen by firms?

In two recent papers, Gravelle and Kotlikoff $(1989,1990)$ used simulation models to estimate the degree to which firms' choices of organizational form should have changed due to differences between the corporate rate and a representative personal tax rate, ${ }^{1}$ and forecast that the effects have been very large. MacKie-Mason and Gordon (1991) examined empirically the degree to which the observed fractions of business income or business assets in corporate and noncorporate firms has changed over time in response to changes in the average tax rates faced on corporate vs. noncorporate income. Income and assets clearly shifted in response to changing tax incentives, but the estimated effects were small.

All these papers suffer from the problem that the difference in average tax rates provides a poor summary of the tax distortions to organizational form choices. Under existing tax incentives, the noncorporate sector should consist of very profitable firms owned by investors in low tax brackets and firms with tax losses owned by investors in high tax brackets. ${ }^{2}$ As a result, a tax change that narrows the distribution of personal tax rates while leaving the average tax rate unchanged would reduce the tax advantage faced by all noncorporate firms. The level and distribution of the taxable rate of return across firms also matters, since tax distortions matter only to the extent to which there is income subject to tax.

In this paper, we develop the theory of the equilibrium allocation of assets between corporate and noncorporate firms more fully. Firms, in deciding on organizational form, must take into account nontax as well as tax factors. ${ }^{3}$ The degree to which firms respond to tax incentives depends on the importance of these nontax factors. Under a variety of simplifying assumptions, we are able to estimate the value of these nontax factors from aggregate data on assets and income of corporate and noncorporate firms, and from information on the distribution of assets across individual tax

\footnotetext{
${ }^{1}$ For a much earlier discussion of the tax distortion to organizational form, see Feldstein and Slemrod (1980).

${ }^{2}$ Firms with tax losses have been an important enough component of the noncorporate sector that aggregate noncorporate income in the United States was negative during the early to mid 1980 s, a situation that cannot be explained by the earlier papers since in these papers the noncorporate tax rates were always below the corporate rate.

${ }^{3}$ As an example of these nontax factors, corporate but not noncorporate firms automatically face limited liability and can list their shares on the public exchanges, in principle making it much easier for them to raise funds from a large number of outside investors.
} 
brackets. The basic intuition is as follows: investors trade off any tax savings from investing in a noncorporate firm, given their tax bracket, with the nontax costs of doing so. Given some assumed size of the nontax costs of operating in the noncorporate form, we model the optimal portfolio holdings in corporate vs. noncorporate firms for investors in each tax bracket. We can then infer how high the nontax costs must have been to make the forecasted fraction of noncorporate holdings in each industry match the observed fraction. We describe the formal model implementing this intuition in Section 2, and derive the resulting empirical estimates in Section 3.

On average, the estimated nontax costs of noncorporate ownership are positive and sizeable: a representative firm would pay costs each year equal to almost $4 \%$ of its equity value by being noncorporate vs. corporate. ${ }^{4}$ In Section 3, we discuss the consistency of these estimates of the nontax costs of operating in noncorporate form with forecasts from the theoretical literature on organizational forms.

In Section 4 we use our estimates to explore the implications of eliminating the separate corporate tax and instead making each shareholder's share of corporate incomc taxablc under his/her personal income tax, as occurs with noncorporate firms. On average, the efficiency gains from the resulting changes in organizational form are forecasted to be only about $9 \%$ of the taxes initially collected on business income. In contrast, Gravelle and Kotlikoff (1989) estimate the efficiency cost from differential taxation to be about $120 \%$ of initial tax revenue.

We relied on many simplifying assumption in the analysis. In Section 5, we discuss possible biases that may result, and report some estimates of the magnitude of these biases. The main findings of the paper are summarized in Section 6.

\section{Model of the equilibrium allocation across organizational forms}

The model has two period. In the first period, firms choose their form of organization and individuals invest in ownership shares in firms. In the second period, firms earn a random return on their investments, taxes are

\footnotetext{
${ }^{4}$ This is the cost averaged across both years and industries. Since noncorporate activity is concentrated in industries where these costs are lower, however, a representative noncorporate firm has only a $1.66 \%$ lower rate of return by remaining noncorporate.

${ }^{5}$ Our results would immediately generalize to a multiperiod setting as long as there are no transactions costs of changing organizational form, so that the decision problem is time separable. For a discussion of the implications of transactions costs for our analysis, see Section 5.
} 
paid both by firms and by individual owners on this income, and the owners consume what is left net of taxes.

There are $I$ different industries in the economy, each with a constantreturns-to-scale production technology. For each dollar invested in a diversified set of corporations in industry $i$, the resulting economic income earned in the second period is a random variable $\tilde{Y}_{i}^{*}$, while the resulting taxable income is denoted by $\tilde{Y}_{i}$. (The ex ante distribution of returns is assumed to be the same for all corporations in an industry.) Let $\tilde{X}_{i}$ denote the difference, $\tilde{Y}_{i}^{*}-\tilde{Y}_{i}$. Corporations are subject to a corporate tax at rate $\tau$, implying corporate tax payments of $\tau \tilde{Y}_{i}$ in the second period. ${ }^{6}$

In addition, corporate equity income is subject to personal taxes. If paid out as dividends, the income is taxed at the investor's full personal tax rate, which we denote as $m_{b}$ for an investor in tax bracket $b$. If retained by the firm, it creates a capital gain for investors, which bears a lower rate of tax due to both exclusion provisions and the deferral advantages of paying the tax at realization rather than upon accrual of the capital gain. On net, corporate equity income bears an effective combined marginal tax rate which we denote by $e_{b i}$ that varies both with the investor's tax bracket and with the (exogenous) dividend payout rate of the industry. We denote the resulting combined tax rate by $\tau_{b i}$, where $\tau_{b i}=\tau+e_{b i}(1-\tau)$. The net income earned on this investment is therefore ${ }^{7} \tilde{Y}_{i}^{*}-\tau_{b i} \tilde{Y}_{i}=\tilde{Y}_{i}\left(1-\tau_{b i}\right)+\tilde{X}_{i}$.

Investors could instead invest the same dollar in the noncorporate sector in industry $i$. The rate of return earned by noncorporate firms will differ to the extent that nontax factors put noncorporate firms at an economic disadvantage. In addition, given the lack of public trading of shares in noncorporate firms and the fact that partnerships are required to refile with the state if their ownership structure changes, investors would find it much more difficult to obtain a diversified portfolio of noncorporate firms in the industry. To capture these effects, we assume that the economic income earned in the second period on a dollar invested in the first period in the noncorporate sector in industry $i$ equals $\tilde{Y}_{i}^{*}-C_{i}+\tilde{\epsilon}_{i}$. Here, $C_{i}$ measures the expected nontax costs of using the capital in the noncorporate sector, ${ }^{8}$ while $\tilde{\epsilon}_{i}$ captures any noise in the size of nontax costs as well as the added risk from having a less well-diversified portfolio. Thus, we allow corporate and

\footnotetext{
${ }^{6}$ For simplicity, we ignore the progressivity in the corporate tax law, so assume that $\tau$ does not vary as a function of $\hat{Y}_{i}$. There was little alternative, given that we are dealing with aggregate rather than firm data.

${ }^{7}$ For simplicity, we ignore any personal taxes on the income $\tilde{X}_{i}$ both here and for noncorporate firms. Tax liability, if any, on this income should take the form of personal capital gains taxes. (Given the General Utilities Doctrine, corporate capital gains taxes should be avoidable.) Since capital gains tax liabilities are low and unaffected by the choice of organizational form, for simplicity we ignored them.

${ }^{8} C_{i}$ need not be positive.
} 
noncorporate returns to differ both in expected value and in variance. By assumption, $\tilde{\epsilon}_{i}$ has variance $\sigma_{i}^{2}$, and is independent of all other random variables in the model. For simplicity, the definition of taxable income is assumed to be the same for corporate and noncorporate firms, ${ }^{9}$ except that the expected nontax costs, $C_{i}$, of operating in the noncorporate sector are assumed to be fully tax-deductible. ${ }^{10}$ We assume that $\tilde{\epsilon}_{i}$ is in the form of capital gains, and ignore any resulting tax liabilities. Therefore, the resulting taxable income in the second period is $\tilde{Y}_{i}-C_{i}$. If the individual owner of this income is in tax bracket $m_{b}$, then the resulting net-of-tax income is ${ }^{11}$ $\tilde{Y}_{i}^{*}-C_{i}+\tilde{\boldsymbol{\epsilon}}_{i}-m_{b}\left(\tilde{Y}_{i}-C_{i}\right)=\left(1-m_{b}\right)\left(\tilde{Y}_{i}-C_{i}\right)+\tilde{X}_{i}+\tilde{\epsilon}_{i}$.

What are the nontax costs (or benefits) of employing capital in the noncorporate sector? The two main costs commonly suggested are first that noncorporate owners face unlimited liability for claims against the firm, and second that they cannot trade ownership shares in public markets. Precisely why these are costs for noncorporations is somewhat disputed. ${ }^{12}$ Nonetheless, it is clear that some costs are offsetting the tax benefits of noncorporate form, or we would see far fewer corporations. Indeed, the statistical evidence in MacKie-Mason and Gordon (1991) suggests that the nontax costs arc morc important in aggregate than the tax effects.

Individual investors make their investment decisions in the first period. In this period, individuals can invest in corporate or noncorporate shares in any industry, or else in a risk-free asset earning a real rate of return $r_{z}-\pi$, and a taxable rate of return of $r_{z}$. ${ }^{13}$ Denote the amount invested in corporate (noncorporate) capital in industry $i$ by investors in tax bracket $b$ by $\alpha_{c i}^{b}\left(\alpha_{n i}^{b}\right)$. Allocation decisions are made so as to maximize a mean-variance utility function: $U=f\left(\bar{I}_{b}, \operatorname{var}\left(\tilde{I}_{b}\right)\right)$, where $\hat{I}_{b}$ is the outcome for second-period

\footnotetext{
${ }^{9}$ For further discussion, see Section 5.

${ }^{10}$ Our estimates of $C_{i}$ in the next section will be too high if in fact the $C_{i}$ are nondeductible. In Section 5 we indicate the size of this possible bias.

${ }^{11}$ Note that here, and in our prior measure of net corporate income, we assume full loss offset. While not strictly available, this seems a reasonable first approximation. In particular, noncorporate owners can deduct losses against other sources of income (e.g. wages, other partnership or portfolio income). Corporations with losses can in principle merge with profitable corporations (perhaps in other industries), and deduct their losses against the other firms' profits. For a discussion of what biases may be created by this simplifying assumption, see Section 5 .

${ }^{12}$ Note that limited liability is only the default rule, and does not prevent firms from contracting around it. Owners of small corporations routinely post personal assets as collateral for financing, and noncorporations routinely enter contracts that limit their liabilities. However, the transactions costs of recontracting may be high, limiting the amount of recontracting. For instance, Katz (1990) shows that if it is costly to contract around the default, even slightly so, adverse selection will prevent anyone from doing so.

${ }^{13}$ In the empirical work, we set $r_{z}$ equal to the nominal Treasury Bill rate and $\pi$ equal to the inflation rate.
} 
income for investors in tax bracket $m_{b}$, and $\bar{l}_{b}$ is its expectation. Following the standard assumptions, $f_{1}>0, f_{2}<0, f_{11}<0$, and $f_{22}<0$. In addition, we assume that investors cannot go short when investing in either sector - short sales would allow individuals to go short in one organizational form and long in the other, arbitraging the tax difference while facing risk only due to $\tilde{\boldsymbol{\epsilon}}_{i}$. Such tax arbitrage is not seen to our knowledge in practice.

In equilibrium, the distribution of organizational forms that businesses choose should equal the distribution desired collectively by individual investors. In particular, businesses should allocate themselves across the alternative forms of organization in each industry until the market values the returns from a dollar of additional investment in each form at a dollar, i.e. when the marginal Tobin's $q$ equals one. In the theoretical derivation, we measure the returns relative to the cost of the underlying investment so as to impose the equilibrium condition that $q$ equals one.

How then do individuals facing tax rate $m_{b}$ divide their portfolios between corporate and noncorporate firms in industry $i$ ? Since the above assumptions are basically those of the capital-asset-pricing model, the first-order conditions characterizing the solution are standard. Starting from the individual's equilibrium portfolio consider the effects of investing a dollar more in the corporate sector in industry $i$. If he already owns positive corporate equity, then by the envelope theorem he would be just indifferent to a further marginal investment; if he owns no such equity, then a marginal investment must be a net loss. After correcting for risk and taxes, the gain from a further corporate investment under the above assumptions, net of the alternative risk-free rate of return, would be measured by

$$
\bar{Y}_{i}\left(1-\tau_{b i}\right)+\bar{X}_{i}-\left(\left(1-m_{b}\right) r_{z}-\pi\right)-G_{b} \operatorname{cov}\left[\left(1-\tau_{b i}\right) \tilde{Y}_{i}+\tilde{X}_{i}, \tilde{I}_{b}\right] \leqslant 0,
$$

where $G_{b} \equiv-2 f_{2} / f_{1}$ measures the individual's degree of risk aversion. Similarly, the net gain from a further noncorporate investment would satisfy

$$
\begin{gathered}
\left(\bar{Y}_{i}-C_{i}\right)\left(1-m_{b}\right)+\bar{X}_{i}-\left(\left(1-m_{b}\right) r_{z}-\pi\right) \\
-G_{b} \operatorname{cov}\left[\left(1-m_{b}\right) \tilde{Y}_{i}+\tilde{X}_{i}+\tilde{\epsilon}_{i}, \tilde{I}_{b}\right] \leqslant 0 .
\end{gathered}
$$

If, in equilibrium, the individual invests in noncorporate but not corporate firms in industry $i$, then Eq. (1b) holds with equality and (1a) with a strict inequality. Combining these two equations and simplifying we find that

$$
\left(\tau_{b i}-m_{b}\right)\left[\bar{Y}_{i}-G_{b} \operatorname{cov}\left(\tilde{Y}_{i}, \tilde{I}_{b}\right)\right]>\left(1-m_{b}\right) C_{i}+G_{b} \alpha_{n i}^{b} \sigma_{i}^{2},
$$

where the last term follows from our assumption that each $\tilde{\epsilon}_{i}$ is uncorrelated with all other random variables in the model. In words, the left-hand side equals the certainty-equivalent tax savings from investing the funds in a 
noncorporate rather than a corporate firm in industry $i$, while the right-hand side measures the expected nontax costs plus the extra risk-bearing costs of investing further in the noncorporate rather than the corporate sector. When the individual chooses not to invest at all in corporate firms in industry $i$, the tax savings must outweigh the nontax costs that result from an additional noncorporate investment. In contrast, if in equilibrium the individual invests in only corporate firms in the industry, then the sign of the inequality in Eq. (2) would be reversed and $\alpha_{n i}^{b}$ would cqual zero in the equation. Eq. (2) would be satisfied with equality at the chosen $\alpha_{n i}^{b}$ if the individual invests in both corporate and noncorporate shares in industry $i$ in equilibrium.

A given investor will normally choose different organizational forms in different industries, and these choices will vary by investor. These results immediately follow from inspection of Eq. (2):

(1) When the nontax or extra risk-bearing costs of noncorporate investments are higher, fewer investors will invest in noncorporate firms.

(2) Noncorporate firms in industries where the certainty-equivalent income is positive (negative) will be relatively most attractive to investors in the lowest (highest) tax brackets. Ownership of noncorporate firms with positive (negative) taxable income should therefore be concentrated among investors in relatively low (high) tax brackets. In combination, this implies that the fraction of assets held in noncorporate form by investors in tax bracket $b$ will be a U-shaped function of the marginal tax rate in that tax bracket.

(3) An increase in the absolute value of the certainty-equivalent taxable income $\bar{Y}_{i}-G_{b} \operatorname{cov}\left(\tilde{Y}_{i}, \tilde{I}_{b}\right)$ makes noncorporate capital more attractive to investors, since tax savings for those who invest in such firms become larger rclative to the nontax costs. Everything else equal, the result is a U-shaped relation between the certainty-equivalent taxable income generated in the industry and the fraction of the assets of the industry held in noncorporate form, a fraction we denote by $F_{i}$.

To illustrate the second result, consider the special case in which $\tilde{Y}_{i}$ generates no risk premium, the variance of the $\tilde{\epsilon}_{i}$ are zero, for simplicity $e_{b i}=\theta m_{b}$ so does not vary by industry, and all the $C_{i}$ are positive. ${ }^{14}$ Given these assumptions, solve Eq. (2) for the personal tax rate, which we denote by $m_{i}$, at which investors in industry $i$ are indifferent to investing in corporate vs. noncorporate firms in that industry, yielding $m_{i}=\left(\tau \bar{Y}_{i}-C_{i}\right) /$

\footnotetext{
${ }^{14}$ When $\tilde{Y}_{i}$ has a positive risk premium, then the variation in $G_{b}$ and $\tilde{I}_{b}$ across brackets complicates the story. (In our data, these risk premia are trivial in size.) If $\tilde{\epsilon}_{i}$ is risky, then this risk limits the size of noncorporate holdings, and in general we cannot conclude that the fraction of holdings held in noncorporate form is $\mathrm{U}$-shaped. If $\theta$ varies with $i$ or some $C_{i}$ are negative, then as an investor's tax bracket rises, he may start purchasing noncorporate firms with tax losses before eliminating all holdings of noncorporate firms with profits, undermining the conclusion that the pattern of noncorporate holdings is strictly U-shaped.
} 


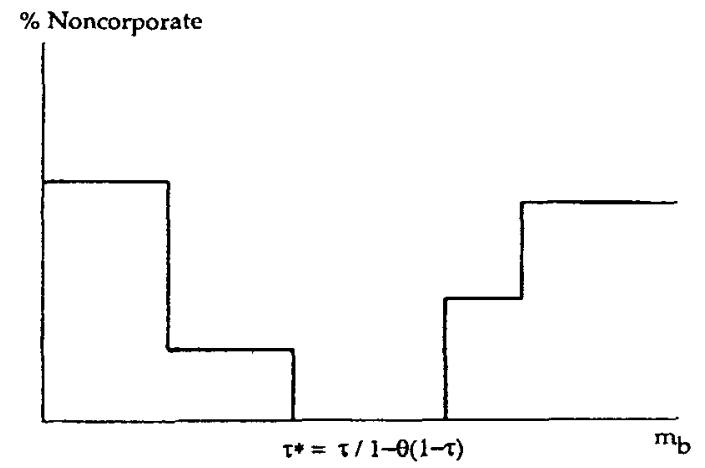

Fig. 1. Relationship between personal tax rates and percentage of noncorporate assets in portfolio, for four industries. $\theta=e_{b} / m_{b}$, where $e_{b}$ is the effective personal tax rate on equity income (see text).

[ $\left.\bar{Y}_{i}(1-\theta(1-\tau))-C_{i}\right]$. If $\bar{Y}_{i}-C_{i}$ is positive (negative), then all investors in a tax bracket higher (lower) than $m_{i}$ invest in corporate firms in industry $i$, and conversely. If all the $C_{i}$ are positive, then investors in a range of personal tax brackets around $\tau /[1-\theta(1-\tau)]$ will invest in only corporate firms. The farther is an investor's tax bracket from this value in either direction, the larger the number of industries in which he will prefer noncorporate to corporate form. If there were four industries, then the fraction of assets held in noncorporate form as a function of $m_{b}$ should have the form illustrated in Fig. 1.

These nonmonotonic relations between personal tax rates or taxable rates of return and the attractiveness of noncorporate investments make any analysis problematic that is based on average figures, such as those in Gravelle and Kotlikoff $(1989,1990)$ or MacKie-Mason and Gordon (1991).

\section{Estimation of nontax benefits of incorporating}

\subsection{Estimation strategy}

Our objective is to estimate the $C_{i}$. The basic strategy is to forecast the aggregate distribution of assets across organizational form by industry using the above model, given the actual data on wealth holdings across tax brackets and taxable rates of return by industry. These forecasts will be a function of the unobserved $C_{i}$. We then solve for those $C_{i}$ that lead the model to forecast an aggregate distribution of assets across forms that matches the distribution observed in the actual data.

To do this, we constructed a data set with most of the variables in the 
model: $\bar{Y}_{i}, \tau, r, m_{b}, e_{b i}$, and the covariance structure of $\tilde{X}_{i}$. In addition to the $C_{i}$, however, we also cannot directly observe the $G_{b}$ or the $\bar{X}_{i}$. Thus, in order to solve the model for the $C_{i}$, we must simultaneously solve for the $\bar{X}_{i}$ and $G_{b}$.

To do this, we start with the system of equations derived above that describes the equilibrium holdings of equity by industry and by organizational form for investors in each tax bracket $b$. For any given values of the $C_{i}$, $G_{b}$, and $\bar{X}_{i}$, we can use expressions (1a) and (1b), along with the nonnegativity constraints for equity holdings of each type, to solve for each investor's pattern of holdings, $\alpha_{n i}^{b}$ and $\alpha_{c i}^{b}$.

We then choose each $G_{b}$ so that the forecasted equity holdings (corporate and non-corporate) in that tax bracket equal the observed holdings in that bracket. Similarly, we choose each $\bar{X}_{i}$ so that the forecasted holdings in that industry equal the observed holdings. Simultaneously, we choose the $C_{i}$ so that the forecasted noncorporate holdings in each industry match the observed noncorporate holdings. In particular, if $W_{b}$ denotes the observed holdings of equity by investors in tax bracket $b$, if $E_{n i}$ equals the observed aggregate holdings of noncorporate firms in industry $i$, and if $E_{i}$ equals the observed aggregate holdings (corporate and noncorporate) in industry $i$, then we have the following three sets of restrictions, which together help us forecast values for all the unobserved parameters:

$$
\begin{aligned}
& \sum_{b}\left(\alpha_{n i}^{b}+\alpha_{c i}^{b}\right)=E_{i}, \\
& \sum_{i}\left(\alpha_{n i}^{b}+\alpha_{c i}^{b}\right)=W_{b}, \\
& \sum_{b} \alpha_{n i}^{b}=E_{n i} .
\end{aligned}
$$

One of these $M+2 N$ equations in system (3) is redundant, however, since it must be that $\Sigma_{i} E_{i}=\Sigma_{b} W_{b}$. As a final restriction, we require that the weighted average expected return on the market portfolio, denoted by $\bar{R}$, be consistent with the historical evidence. To solve for the theoretical relation characterizing $\bar{R}$, we first divide all terms in Eq. (1a) by $G_{b}$ and sum over those tax brackets $\left\{b_{i}\right\}$ that own corporate equity in industry $i$, giving ${ }^{15}$

$$
\bar{Y}_{i}\left(1-\tau_{i}^{*}\right)+\bar{X}_{i}=r\left(1-m_{i}^{*}\right)-\pi+\gamma_{i} \operatorname{cov}\left(\tilde{X}_{i}, \sum_{b \in\left\{b_{i}\right\}} \tilde{I}_{b}\right) .
$$

Here, $\quad \gamma_{i}=1 /\left[\sum_{b \in\left\{b_{i}\right\}}\left(1 / G_{b}\right)\right], \quad m_{i}^{*}=\gamma_{i}\left[\sum_{b \in\left\{b_{i}\right\}}\left(m_{b} / G_{b}\right)\right], \quad$ and $\tau_{i}^{*}=$ $\left.\left.\gamma_{i}\left[\Sigma_{b \in\left\{b_{i}\right\}}\right\} \tau_{b i} / G_{b}\right)\right]$. Let $E_{c i} \equiv E_{i}-E_{i n}$ denote the value of corporate equity

\footnotetext{
${ }^{15}$ We find below that in the data the risk premium for the $\tilde{Y}_{i}$ are trivial in size, so we ignore these terms in this expression.
} 
in industry $i$. Then if we weigh Eq. (4) by $E_{c i}$, sum over $i$, and divide through by $\Sigma_{i} E_{c i}$, we find that

$$
\bar{R} \equiv\left(\sum_{i}\left[\left(1-\tau_{i}^{*}\right) \bar{Y}_{i}+\bar{X}_{i}\right] E_{c i}\right) / \sum_{i} E_{c i}=r\left(1-m^{*}\right)-\pi+\Omega
$$

where $m^{*}=\Sigma_{i} E_{c i} m_{i}^{*} / \sum_{i} E_{c i}$ and where $\Omega$ is a similarly weighted average of the risk-premium terms in Eq. (4). Market data were used to estimate the right-hand side of Eq. (5), ${ }^{16}$ creating the final restriction needed to identify all the needed parameters.

It should be noted that our results are not conventional econometric estimates with estimable standard errors. To begin with, all of our data series are estimated with some error, and then used to estimate the $C_{i}$ with zero degrees of freedom; we get a perfect 'fit'. As a result, we are not in a position to report standard errors for our estimates.

\subsection{Data}

We require data for corporate expected returns $\left(\bar{Y}_{i}\right)$, asset holding by industry and type of organization $\left(E_{i}, E_{n i}\right)$, wealth by tax bracket $\left(W_{b}\right)$, the covariance structure of equity returns, and various tax parameters. To construct these variables we use data from the U.S. IRS Statistics of Income files, the CRSP security price files, the Compustat corporate financial statement files, the U.S. Federal Reserve Flow of Funds accounts, and miscellaneous other sources. We describe the construction of our data in an unpublished appendix. ${ }^{17}$ In this subsection we describe the nature of the data and some of the more important assumptions we had to make to construct our variables.

Under U.S. tax law, the noncorporate sector comprises a diverse set of firms. Noncorporate firms with a single owner could report their income on Schedule C (proprietorship income), schedule E (rental income), or schedule $\mathrm{F}$ (farming income). ${ }^{18}$ Noncorporate firms with multiple owners (partnerships) are reported separately on the tax forms. There is an additional form of organization in the United States, a subchapter-S corporation, which has limited liability but is taxed the same as other

\footnotetext{
${ }^{16}$ We used historical data for $r$ and $\pi$, and used our model to estimate $m^{*}$. For the market risk premium, $\Omega$, we use an estimate of $6.8 \%$ that was reported in Table $4.5 \mathrm{c}$ in Merton (1980), estimated over the period $1966-78$.

${ }^{17}$ This appendix, along with the final data set, is available on request.

${ }^{18}$ Unfortunately, the IRS did not report information on schedule F income after 1980, so that our sample for the farming industry consisted of 1970 and 1972-80.
} 
noncorporate forms. ${ }^{19}$ Since they face the same tax treatment as noncorporate firms, we include $S$ corporations in the noncorporate sector.

To construct our estimates of corporate expected returns $\left(\bar{Y}_{i}\right)$ and asset ownership $\left(E_{n i}, E_{i}\right)$, we relied primarily on data from the U.S. IRS Statistics of Income data files. This data source restricted our sample to the years 1970 , and $1972-86 .^{20}$ These publications report aggregate income statements and some balance sheet data for corporate and noncorporate firms. We are limited to 1-digit industry data because greater disaggregation was not available for all organization types.

From these data we imputed the market value of both the corporate and the noncorporate equity held each year by individuals. To do so, we started by constructing data on the aggregate market value of corporate and noncorporate equity. Several complications were faced in this initial step. First, market values of equity are observed only for publicly-traded corporations. For other corporations and for partnerships, only the book value of equity used for accounting purposes is observed; here, we assumed that the ratio of the market value to the book value among these firms is the same as that for publicly-traded corporations in the same industry. ${ }^{21}$

Since the corporate shares not held by other corporations own the entire corporate sector, the market value of the assets in the corporate sector should equal the value of these outside shares alone. To measure the value of outside shares, we estimated the size of the cross-holdings of equity among publicly traded corporations in each industry, ${ }^{22}$ then subtracted this value from the market value of all shares outstanding in each industry. (These corrected market value figures were used in the ratios described in the previous paragraph.)

\footnotetext{
${ }^{19} \mathrm{~S}$ corporations face severe limits on the number and kind of owners they can have, however, limiting their economic importance.

${ }^{20}$ Unfortunately, the government's archive tape for 1971 was constructed improperly, making it unreadable.

${ }^{21}$ In some years, the partnership data includes book assets but not book equity. In these years, we interpolated figures for book debt by multiplying the observed interest payments in that year by the average ratio of book debt to interest payments in the adjoining years in that industry. For some noncorporate forms, only the income statement is observed; here, we assumed that the ratio of depreciation deductions to market value is the same as for publicly-traded corporations. In a few years, depreciation deductions were missing as well. In these cases, values were imputed using depreciation deductions in adjoining years.

${ }^{22}$ Corporations own shares in other corporations both directly (e.g. shares in their subsidiaries) and indirectly (e.g. shares used to fund their defined-benefit pension plans). The value of shares held directly were estimated based on the dividends that corporations report receiving, under the assumption that the payout rate on these shares equals the aggregate payout rate in the industry as a whole. Estimates of the value of shares held in defined-benefit pension plans were constructed using data from the Federal Reserves' Flow of Funds and from Kotlikoff and Smith (1983).
} 
Our theory focuses on the allocation of shares taxable under the personal income tax. We used Federal Reserve Flow of Funds data to delete equity holdings not subject to the personal income tax, e.g. owned by foreigners or defined-contribution pension plans. ${ }^{23}$ We report the resulting estimates of the fraction of equity held in noncorporate form in each industry, $F_{i}$, averaged across the sample period, in column (1) of Table 1 . We report the average value of $F_{i}$ in each year, averaged across industries, in column (1) of Table 2.

Our next step was to calculate the expected taxable rates of return earned within the corporate sector, $\bar{Y}_{i}$. For a given industry in a given year, we set $\tilde{Y}_{i}$ equal to the ratio of the total taxable income reported by corporations to our estimate of the total market value of corporate equity for these firms (before the above adjustments). Expected taxable rates of return, $\bar{Y}_{i}$, were then estimated based on a regression of the ex post values against lagged data ${ }^{24}$ The resulting estimates for $\bar{Y}_{i}$ by industry, averaged over the sample period, are reported in column (2) of Table 1. Overall, these estimates seem quite reasonable, except that for the mining industry. ${ }^{25}$

We next constructed data on the total equity holdings, $W_{b}$, of investors in each tax bracket $b$ in each year, based on samples of individual tax returns in each year. ${ }^{26}$ For investors in each tax bracket, we had data on their dividends from corporate holdings, and their income from each type of noncorporate holdings (as reported on tax schedules C, E, and F). In each case, we allocated the aggregate market value for each type of asset held directly by individuals, as estimated above, across tax brackets in proportion to the income from that type of asset reported by individuals in that tax bracket. ${ }^{27}$ For $W_{b}$ we then summed the equity holdings of investors in tax bracket $b$.

\footnotetext{
${ }^{23}$ Since this data source does not break down share holdings by industry, we had to assume that such holdings were fully diversified.

${ }^{24}$ We assumed an ARMA $(1,1)$ process for each of the variables being forecast, and included the lagged value of the rate of return for the entire corporate sector. In one case, the moving average term was not included because the estimate was outside the stable region. Our time series were too short to justify more complicated models.

${ }^{25}$ The several sharp jumps in oil and other mineral prices during our sample period resulted in large windfalls to this industry.

${ }^{26}$ The data are from the IRS Individual Model Files. We thank the Center for Tax Policy Research at the University of Michigan for providing these data and assistance in using them. The number of individual tax returns in the sample each year ranged from about 70,000 to about 110,000 .

${ }^{27}$ This was done separately for income from corporate dividends, proprietorships, rental property, farms, and subchapter $S$ corporations. For each noncorporate form of income, we estimated separately the value of equity in firms reporting losses vs. profits, and allocated each across tax brackets in proportion to the amount of losses (profits) from this noncorporate form reported by individuals in that tax bracket.
} 


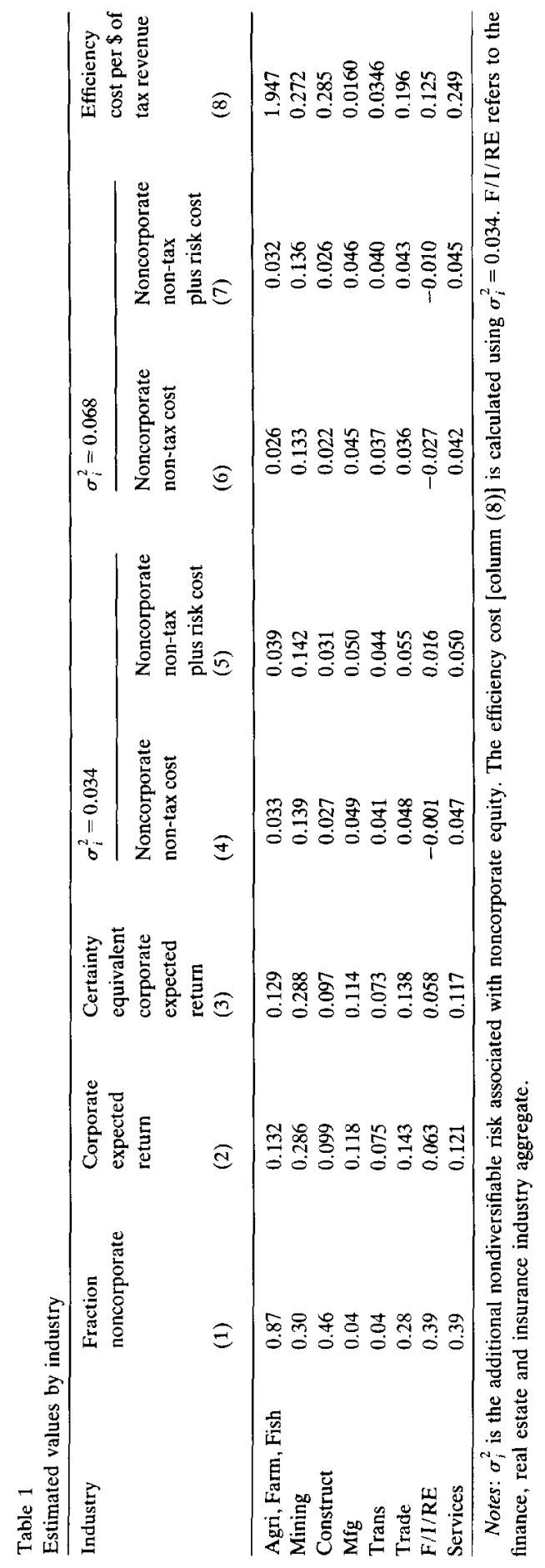


Table 2

Estimated values by year.

\begin{tabular}{lllll}
\hline Year & $\begin{array}{l}\text { Fraction } \\
\text { noncorporate } \\
\left(F_{i}\right)\end{array}$ & $\begin{array}{l}\text { Max(pers. tax rate) } \\
\text { minus } \\
\max (\text { corp. tax rate) } \\
(\Delta t)\end{array}$ & $\begin{array}{l}\text { Wtd. avg. } \\
\text { noncorporate } \\
\text { non-tax cost } \\
\left(C_{i}\right)\end{array}$ & $\begin{array}{l}\text { Efficiency cost } \\
\text { per \$ of } \\
\text { tax revenue }\end{array}$ \\
& $(1)$ & $(2)$ & 0.0221 & $(4)$ \\
\hline 1970 & 0.23 & 0.22 & -0.00889 & 0.0935 \\
1972 & 0.31 & 0.22 & 0.0297 & 0.00491 \\
1973 & 0.22 & 0.22 & 0.0380 & 0.0692 \\
1974 & 0.22 & 0.22 & 0.0634 & 0.0408 \\
1975 & 0.18 & 0.22 & 0.0790 & 0.103 \\
1976 & 0.22 & 0.22 & 0.0500 & 0.135 \\
1977 & 0.21 & 0.22 & 0.0541 & 0.0869 \\
1978 & 0.21 & 0.22 & 0.0612 & 0.0743 \\
1979 & 0.19 & 0.24 & 0.0751 & 0.168 \\
1980 & 0.22 & 0.24 & 0.0290 & 0.0686 \\
1981 & 0.22 & 0.24 & 0.0342 & 0.0919 \\
1982 & 0.18 & 0.04 & 0.0204 & 0.0896 \\
1983 & 0.21 & 0.04 & 0.0214 & 0.0689 \\
1984 & 0.21 & 0.04 & -0.00244 & 0.0303 \\
1985 & 0.27 & 0.04 & 0.0171 & 0.174 \\
1986 & 0.28 & 0.04 & & \\
\hline
\end{tabular}

To calculate the risk premium for $\tilde{Y}_{i}$ in each industry, we first estimated the market $\beta$ for $\tilde{Y}_{i}$ in each industry by regressing $\tilde{Y}_{i}$ against the return on the S\&P 500, using annual data for the period $1970-86 .{ }^{28}$ We then multiplied this estimate of $\beta$ by Merton's estimate for the risk premium on the market portfolio of $6.8 \%$, in order to derive an estimate of the risk premium for $\tilde{Y}_{i}$. The resulting certainty-equivalent values for the $\tilde{Y}_{i}$, averaged over our sample period, are reported in column (3) of Table 1.

Everything else equal, the theory forecasts that the fraction noncorporate in an industry should be a U-shaped function of the certainty-equivalent taxable income generated in that industry, with the minimum fraction noncorporate being in industries with no certainty-equivalent taxable income. Since almost all the certainty-equivalent values were positive, we simply tested to see whether there was a positive correlation between these values and $F_{i}$ among those observations where the certainty-equivalent values were positive. The resulting correlation was in fact positive, but equal

\footnotetext{
${ }^{28}$ The S\&P 500 consists of large firms, but our theory assumes that investors hold diversified portfolios of both large and small firms. However, on an annual basis the S\&P 500 returns is quite correlated with broader indices. Given the extremely small relationship we found between annual taxable income by industry, $Y_{i}$, and the S\&P 500 return, we do not expect the choice of index to have a significant effect on the results.
} 
to only $0.016 .^{29}$ This one-dimensional test ignores, however, variation in the $C_{i}$ across industries, or variation in $C_{i}$, the tax law and the wealth distribution across time, or a systematic relationship between the risk aversion parameters $G_{b}$ and tax rates $m_{b}$.

Before proceeding, note in comparing columns (2) and (3) that there is almost no risk premium attributed to the taxable return $\tilde{Y}_{i}$-almost the entire risk premium in corporate equity is attributed to the nontaxable component, $\tilde{X}_{i}$. For simplicity, in the rest of the analysis we will therefore assume that $\tilde{Y}_{i}$ is risk free, so that the certainty-equivalent value of $\tilde{Y}_{i}$ will be measured by $\tilde{Y}_{i}$.

In order to estimate the various covariances in the model, we set $\tilde{I}_{b}$ equal to the investor's total return from corporate and noncorporate equity, $\Sigma_{i}\left[\alpha_{c i}^{b}\left(\bar{Y}_{i}\left(1-\tau_{b i}\right)+\tilde{X}_{i}\right)+\alpha_{n i}^{b}\left(\bar{Y}_{i}\left(1-m_{b}\right)+\tilde{X}_{i}+\tilde{\epsilon}_{i}\right)\right]^{30}$ We then estimated the covariances among the various $\tilde{X}_{i}$ using data from the CRSP files on daily corporate rates of return. In doing so, we aggregated by industry and pooled data from the current and previous years.

We saw no convincing way to estimate the size of the extra idiosyncratic variance, $\sigma_{i}^{2}$, faced when investing in noncorporate shares. In most of our results, we simply assumed that noncorporate income was roughly twice as risky as corporate income. In particular, we set $\sigma_{i}^{2}$ equal to the variance of the return on the market portfolio of corporate stocks, which we estimated to equal 0.034 . As a sensitivity test, we also report some results where $\sigma_{i}^{2}$ is twice as large.

For tax rates we used the statutory corporate and personal tax rates in effect for each year. Depending on the year, the number of personal tax brackets ranged from 24 (in 1982) to 46 (in 1972) ${ }^{31}$ The corporate tax rate is in fact graduated as well, with a lower rate on income below a certain threshold ( $\$ 75,000$ in 1985 , for example). However, the rate of return data could not be constructed separately for each corporate tax bracket, so we use only the top corporate tax rate. Since the top rate begins at a rather low level of income we do not expect that ignoring the lower tax bracket has much significance for our results. We report the difference between the top personal and corporate tax rates as $\Delta t$ in column (2) of Table 2.

To calculate the effective combined marginal tax rate on corporate equity

\footnotetext{
${ }^{29}$ This correlation is calculated deleting the figures for the mining industry. Rates of return for mining during 1974-80 were such outliers that they dominated the results.

${ }^{30}$ In general, the probability distribution of future consumption $\tilde{I}_{b}$ in Eqs. (1a) and (1b) can be affected by many factors other than the returns on corporate and noncorporate equity owned directly, e.g. uncertain labor earnings or risk in the value of nonfinancial and other financial assets. We capture the effects of these other sources of risk only implicitly by choosing the value of $G_{b}$ to rationalize the observed portfolio choices.

${ }^{31}$ A given individual faces far fewer potential tax brackets, but the schedules are different for various taxpayer categories (e.g. married, single, single head of household).
} 
income, $\tau_{b i}$, we take the dividend payout ratio in each industry $i$, denoted by $d_{i}$, to be an exogenous parameter, and measure it as the ratio of total dividends paid to taxable income in that industry, as reported in the IRS Statistics of Income tables. Then, to calculate the effective tax rate on the portion of equity income that is accrued as a capital gain, we first apply the statutory capital gains exclusion factor $(50 \%$ before October $1975 ; 60 \%$ thereafter), which we denote by $g$. We then multiply by a factor $a$ to convert the tax rate on realized gains into a tax rate on the present value of accrual equivalent gains. Following Feldstein et al. (1983), we set $a$ equal to $0.25 .^{32}$ Thus, we calculate the effective personal tax rate on equity income as $e_{b i}=d_{i} m_{b}+\left(1-d_{i}\right) g a m_{b}$.

\subsection{Estimation results}

We now present the results from the estimation strategy described in the previous subsection, ${ }^{33}$ solving each year separately. Our estimates for $C_{i}$ for each industry, averaged over time, are reported in column (4) of Table 1. Except for the figure for the mining industry, where taxable profits were incredibly high due to the windfalls during the $1970 \mathrm{~s},{ }^{34}$ these numbers look quite reasonable. Among the other industries, the annual expected nontax cost, $C_{i}$, of operating in the noncorporate form ranges from a high of just about 0.05 in the manufacturing, trade, and services industries to a low of -0.001 in the finance/insurance/real estate industry. Recall that the $C_{i}$ are measured in the same units as rates of return on equity. Compared with our estimates of the expected taxable rate of return, $\bar{Y}_{i}$, or the estimate of about 0.105 for the expected economic rate of return in the corporate sector found in Feldstein and Summers (1977), these figures are large in economic terms.

The extra marginal costs from choosing a noncorporate form also include the extra risk-bearing costs, however. We calculated weighted averages of the extra risk-bearing costs, $G_{b} \alpha_{n i}^{b} \sigma_{i}^{2}$, weighting the value in each tax

\footnotetext{
${ }^{32}$ In the United States the tax rate is reduced to zero if assets are held until the owner's death or if donated to charity.

${ }^{33}$ Our first attempt to measure $C_{i}$ involved estimating the taxable rates of return within the noncorporate sector, $\vec{Y}_{i}-C_{i}$, then subtracting these returns from those in the corporate sector to estimate $C_{i}$. Unfortunately, the resulting figures for $\bar{Y}_{i}-C_{i}$ were not credible. For example, the resulting estimate of the average yearly expected taxable rate of return in the noncorporate service sector during the sample period was $165 \%$ ! The likely explanation is that noncorporate firms often choose to include labor income of the owners in their reported taxable income doing so has only small tax consequences (through, for example, effects on social security and unemployment insurance payments) and may be useful for nontax reasons.

${ }^{34}$ Ignoring the years most affected by the 'oil shocks', 1974-80, the average $C_{i}$ in mining was only 0.037 .
} 
bracket by its ownership share $\alpha_{n i}^{b}$, and added these risk-bearing costs to the expected nontax costs, $C_{i}$. The resulting figures for the combined costs of choosing a noncorporate form are reported in column (5) of Table 1. Clearly the risk-bearing costs play a minor role, at least given the assumed values of the $\sigma_{i}^{2}$. To test the sensitivity of our results to the value of $\sigma_{i}^{2}$, we doubled the assumed values for the $\sigma_{i}^{2}$ to 0.068 . The resulting cost estimates are reported in columns (6) and (7), and show little sensitivity to the assumed value of the $\sigma_{i}^{2}$. This occurs in part because the greater riskiness of noncorporate investments is offset by the slightly smaller values of the $C_{i}$ now needed to rationalize the observed choices.

\subsection{Discussion}

Ours is the first study of which we are aware that provides direct estimates of the size of nontax factors that affect the relative attractiveness of corporate and noncorporate organizational forms. To what extent are our estimates consistent with theoretical discussions? In two recent papers, Fama and Jensen (1983a,b) discuss the role of share liquidity for the choice of organizational form. They assume that equity in noncorporate firms, being much less liquid, ends up being owned primarily by close personal associates of those running the business. While concentrated ownership reduces problems arising from separation of ownership from control, it imposes higher risk-bearing costs and limits the amount of capital that can he raised easily. These costs should be higher in industries where firms are larger, making access to capital markets more important; they should also be higher in industries that face greater diversifiable risk, risk that should impose no real cost on (publicly traded) corporations but that will likely be costly for owners of noncorporate firms to bear.

One clear piece of evidence on the importance of equity liquidity and ownership concentration is the relatively small size of the $S$ corporation sector in the United States. $S$ corporations have the same limited liability rules as do regular corporations, but the tax rules of a partnership. To qualify a firm must accept significant restrictions on the number and identity of shareholders. For example, under current law, there may be no more than 30 shareholders, none of whom may be corporations or forcign citizens. Evidently these constraints on diversified ownership are quite costly; otherwise we would expect to see far more $\mathbf{S}$ corporations.

To judge the consistency of our estimates with this theory, we regressed $C_{i}$ against two variables intended to measure the value of capital market access and the costs of additional risk-bearing. The first, denoted by $v_{i}$, is the average equity value per firm in the industry, including both noncorporate and corporate firms, measured in billions of 1982 dollars. The larger is $v_{i}$ the more costly should be the lack of access to capital markets for 
noncorporate firms, leading to a higher value of the nontax costs $C_{i}$ of operating in noncorporate form. The second variable, denoted by $s_{i}$, is the root-mean-squared-error from a regression each year of the daily rate of return of NYSE firms in industry $i$ against the market rate of return. ${ }^{35}$ This variable measures the size of diversifiable risks in each industry; when these risks are more important, the noncorporate form should be less attractive, making $C_{i}$ larger. In fact, we found that

$$
\begin{gathered}
\hat{C}_{i}=0.031+0.050 v_{i}+0.68 s_{i}, \\
(0.014)(0.022) \quad(1.71)
\end{gathered}
$$

with an $R^{2}$ of 0.05 and standard errors reported in parentheses. Both estimated coefficients have the expected sign, that for $v_{i}$ is statistically significant, and both are large in economic terms. An increase in $v_{i}$ by one standard deviation, for example, increases $C_{i}$ by 0.016 . The observed values of $s_{i}$ are normally around 0.003 but range as high as 0.016 , suggesting somewhat smaller but still important potential effects on $C_{i}$.

Regulations are another factor that may affect the relative cost of corporate and non-corporate forms. In column (3) of Table 2, we report the weighted average estimate of $C_{i}$ in each year, weighted by the equity outstanding in each industry. There were two important regulatory changes during this period. In 1976, 'at-risk' rules were introduced for partnerships to restrict the deductibility of losses, thereby making this noncorporate form less attractive. In addition, in 1982 several regulations affecting subchapter $\mathrm{S}$ corporations were relaxed, making this noncorporate form more attractive. ${ }^{36}$ While the average values of $C_{i}$ are higher in the last half of the 1970s and lower in the 1980s, consistent with these forecasts, the change in each case appears to occur a year preceding the forecasted date. We also see a sharp growth in the size of $F_{i}$ and a decrease in $C_{i}$ starting in 1985, appearing to anticipate the tax changes that were enacted in 1986 affecting tax years starting in $1987 .^{37}$ If firms face important costs of changing organizational form, then they would have an incentive to anticipate coming changes in the tax and regulatory code. Our observations suggest they in fact do so.

\footnotetext{
${ }^{35}$ Since we made no attempt to measurc variation in $\sigma_{i}$ by industry our estimates for $C_{i}$ include any variation in risk-bearing costs across industries.

${ }^{36}$ There were also less important regulatory changes in 1973 and 1983. Neither was found to matter much in the tests reported in MacKie-Mason and Gordon (1991). Given our limited data, we restrict our discussion to the two major regulatory changes.

${ }^{37}$ Certainly, the huge realizations of capital gains by individuals that occurred in 1986 would be consistent with this reading.
} 


\section{Implications of partnership tax treatment of corporate income}

Economists have long advocated eliminating the corporate tax and instead making each shareholder pay tax on his/her share of corporate income under the personal income tax. ${ }^{38}$ In many countries, this outcome is approximated through the use of dividend imputation schemes.

In this section we use our model estimates to forecast the efficiency consequences of the changes in organizational form that would result from introducing such a tax reform in the United States. Specifically, we examine the alternative tax system under which corporate taxable income, $\bar{Y}_{i}$, is taxed at the personal tax rate of the owner, $m_{b}$, rather than at the corporate tax rate. Under such a tax system, following the logic used in deriving Eq. (2) we find that investors in tax bracket $m_{b}$ would invest in noncorporate firms until ${ }^{39}$

$$
\left(1-m_{b}\right) C_{i}+G_{b} \sigma_{i}^{2} \sigma \alpha_{n i}^{b} \leqslant 0,
$$

where the inequality would be strict when $\alpha_{n i}^{b}=0$. It follows immediately that there would be no investment in the noncorporate form in any industry $i$ in which $C_{i}>0$. If $C_{i}<0$, however, then each investor would choose $\alpha_{n i}^{b}$ such that Eq. (2a) holds with equality. Any further investment in industry $i$ would then be in corporate equity. ${ }^{40}$

We calculate the efficiency consequences of allocating an amount of capital $E_{n i} \equiv \Sigma_{b} \alpha_{n i}^{b}$ to noncorporate rather than corporate firms by aggregating the changes in certainty-equivalent individual incomes plus the change in tax revenue. The drop in tax revenue plus the drop in expected income of individuals is measured simply by the aggregate nontax costs, $E_{n i} C_{i}$, while the increase in aggregate risk-bearing costs is given by $0.5 \sigma_{i}^{2} \Sigma_{b} G_{b}\left(\alpha_{n i}^{b}\right)^{2}$. The drop in these combined costs, summed across

\footnotetext{
${ }^{38}$ For one such proposal, see McLure (1979).

${ }^{39}$ For simplicity, we assume here that corporate investment remains positive in each industry in equilibrium - when there is no corporate investment, Eq. (1b) would be used instead to determine the equilibrium value of $\boldsymbol{\alpha}_{n i}^{b}$. We tested the importance of this simplification for the last few years of our sample, estimating the equilibrium portfolio choices for all investors, holding aggregate capital in each industry constant, and obtained quite similar results.

${ }^{40}$ Note that even under this tax system taxes affect the organizational form decision, discouraging use of the noncorporate form. This occurs due to our assumption that the gain from noncorporate investments (when $C_{i}$ is negative) is taxable, but that the offsetting cost due to the extra risk is not shared with the government. In principle, reallocating these idiosyncratic risks from noncorporate investments through the tax system could result in an efficiency gain, making noncorporate investment more attractive. Achieving this would require a more extensive tax reform than the one considered here, however.
} 
industries, in response to the shift to partnership tax treatment of corporate income measures the efficiency gain from this tax reform resulting from the changes in organizational form per se. ${ }^{41}$

We averaged the resulting figures across time for each industry and report them in column (8) of Table 1 , and across industries for each year and report them in column (4) of Table 2. In order to aid in the interpretation of the resulting figures, we express them as a percent of the tax revenue that would have been collected had the entire industry been corporate. ${ }^{42}$ Averaged across the full sample, the increase in efficiency due to changes in organizational form is only $8.7 \%$ of the initial tax revenue from these firms. This estimate seems quite consistent with the very limited responsiveness of organizational form decisions to taxes found by MacKie-Mason and Gordon (1991). Our estimates do differ dramatically by industry and fluctuate over time, suggesting the importance of omitted factors (some of which we discuss below). In farming, for example, before the tax reform on average $87 \%$ of capital was invested in noncorporate firms. Since our estimate of $C_{i}$ for this industry is positive in all but one year, except in that year all of these firms should choose to incorporate under the proposed tax reform according to the theory, resulting in an estimated efficiency gain which is one and a half times the revenue collected from this industry.

The estimated efficiency cost is notably higher in three years: 1976, 1980 and 1986. The jump in 1976 is primarily due to unusually high estimated nontax costs for the construction and services industries, due to high estimates for the $\vec{Y}_{i}$ in this year. This may simply reflect noise in our estimates for $\bar{Y}_{i}$.

The high estimated efficiency costs in 1980 and 1986 are largely due to a sharp rise in the fraction noncorporate in each year. In each case, a tax reform went into effect the next year which lowered personal rates substantially relative to corporates rates, thereby making the noncorporate form more attractive. Investors appear to be changing their choices for organizational form in anticipation of these future tax changes, consistent with the presence of significant transaction costs of changing form. Since the noncorporate sector is larger under the distorting tax system, the efficiency cost of the tax distortions are estimated to be larger.

We are aware of only one other published paper that provides measures

\footnotetext{
${ }^{41}$ Such a tax reform would affect aggregate efficiency in a variety of other ways. In particular, it would cause real capital to be reallocatcd across industries, cause a shift between investments in bonds vs. real capital, cause a change in the allocation of risks across tax brackets, and cause a change in total savings. We did not attempt to model the productive sector, savings hehavior, or equilibrium output prices, so were not in a position to forecast these other efficiency implications of the tax reform.

${ }^{42}$ If actual corporate tax payments in year $t$ in industry $i$ were $T_{i t}$, then we projected that revenue would have been $T_{i t} /\left(1-F_{i}\right)$ had all firms in the industry been corporate.
} 
of the efficiency costs from tax distortions to organizational form, by Gravelle and Kotlikoff (1989). Their results are strikingly different: they estimate an efficiency gain from partnership taxation of about $120 \%$ of the tax revenue collected, versus our average $9 \%$ gain. Why are the results so different?

The excess burden estimates can be approximated by $-0.5 \Sigma_{i} t_{i} \Delta E_{n i}$, where $t_{i}$ is the initial tax distortion discouraging incorporation in the $i$ th industry, and $\Delta E_{n i}$ is the change in noncorporate holdings caused by the shift to a partnership tax treatment of corporate income. Both papers forecast that $E_{n i} \approx 0$ under a partnership tax treatment of corporate income. ${ }^{43}$ While we calculate that historically the noncorporate sector has contained only about $20 \%$ of the capital stock, however, Gravelle and Kotlikoff (1989) assume that the noncorporate shares in their two industries are $98.3 \%$ and $37 \%$, respectively, causing their estimate for $\Delta E_{n i}$ to be two to five times as large as ours. In addition, they assume that personal tax liabilities are unaffected by the choice of organizational form, so that $t_{i}$ simply equals the corporate tax rate, $\tau$. In contrast, our estimate of the tax distortion faced by the marginal firm choosing noncorporate form is $[\tau+$ $\left.\theta_{i} m_{i}(1-\tau)\right]-m_{i}$, where $m_{i}$ is the tax bracket at which investors are just willing to buy some noncorporate shares in industry $i$. Not only is this distortion smaller than $\tau$, but by construction it is smaller particularly in those industries with large noncorporate shares, where we infer that $m_{i}$ must be close to $\tau$ in order to explain the large size of noncorporate holdings in the industry. These smaller estimate for the $t_{i}$ explain most of the rest of the differences in the two sets of results.

\section{Possible biases in the estimates of $C_{i}$}

Many simplifying assumptions were used above in deriving estimates of the nontax costs of not incorporating. In this section we examine how our estimates are likely to change when some of these assumptions are relaxed. In some cases, tests for the size of possible biases are described, and at the end of the section we estimate their importance.

\subsection{Allowing for heterogeneity in $C_{i}$ within an industry}

So far, we have assumed that the nontax costs, $C_{i}$, of noncorporate form are the same for all equity invested in a given industry. If $C_{i}$ varies across firms within an industry, then those firms with the lowest values of $C_{i}$ would

\footnotetext{
${ }^{43}$ In our model, noncorporate firms would survive only in industries with negative estimates for $C_{i}$, which occur primarily in the finance/insurance/real estate industry.
} 
be the ones that become noncorporate. Our procedure would still estimate the correct value of $C_{i}$ for the marginal noncorporate firm, but would overestimate the aggregate efficiency loss of the tax distortions to organizational form, implying that our efficiency cost estimates are upper bounds.

\subsection{Assuming that the $C_{i}$ are tax-deductible}

We assumed in the model that the nontax costs of noncorporate form were tax-deductible. However, it is possible that some of the nontax costs may not be tax-deductible, e.g. they arise during bankruptcy proceedings when the firm has no taxable income in any case. To test the sensitivity of our results to this assumption, consider what happens if we make the opposite assumption that all $C_{i}$ are nondeductible. Then if we denote our (incorrect) estimates above as $\tilde{C}_{i}$, and the correct estimates as $\hat{C}_{i}^{*}$, the relation between the two is given by ${ }^{44}$

$$
\hat{C}_{i}^{*}=\hat{C}_{i}\left[\sum_{b \in N_{i}} \frac{\left(1-m_{b}\right)}{G_{b} \sigma_{i}^{2}} / \sum_{b \in N_{i}} \frac{1}{G_{b} \sigma_{i}^{2}}\right],
$$

where $N_{i}$ denotes the set of tax brackets in which investors own positive amounts of noncorporate equity in industry $i$. Our estimate, $\hat{C}_{i}$, then overestimates the correct $\hat{C}_{i}^{*}$ by a factor equal to a weighted average (over those who own noncorporate stock) of the individual tax factors, $\left(1-m_{b}\right)$.

\subsection{Allowing for heterogeneity in $\bar{Y}_{i}$}

Another implicit assumption made above is that all firms in a given industry earn the same taxable rate of return on their capital. Yet 1-digit industries are very heterogeneous. For example, our estimates of $\bar{Y}_{i}$ were normally positive, yet certain subindustries, e.g. real estate and oil and gas drilling, have consistently generated negative taxable income, making them appropriate as investments for those in high tax brackets. Given heterogeneity of $\bar{Y}_{i}$ within an industry, the noncorporate sector in each industry should be composed of those firms with either very positive or very negative values of $\bar{Y}_{i}$.

Ignoring the possible presence of heterogeneity in $\bar{Y}_{i}$ within an industry causes us to underestimate the value of $C_{i}$. To see this, consider the case in which the average $\bar{Y}_{i}$ is positive. Given heterogeneity in $\bar{Y}_{i}$, the value of $\bar{Y}_{i}$ for the marginal noncorporate firm owned by low-tax-bracket investors in

\footnotetext{
${ }^{44}$ We assume here that Eq. (2) is satisfied with equality for all investors who own noncorporate stock. The expression for the $\hat{C}_{i}^{*}$ becomes messier, but should not change much quantitatively, if this is not true.
} 
theory should exceed that for any remaining corporate firm. Yet we used the mean value for $\bar{Y}_{i}$ among corporate firms in estimating $C_{i}$, and a smaller value of $\bar{Y}_{i}$ leads to a smaller estimate of $C_{i}$. In addition, when some noncorporate firms are in fact owned by those in high tax brackets, fewer noncorporate firms are owned by low-tax-bracket investors than we estimate, requiring an increase in $C_{i}$ to rationalize this outcome.

\subsection{Differences in reported income of corporate and noncorporate firms}

So far, we have assumed that a firm's taxable income is unchanged if it changes its organizational form, other than due to the extra real costs, $C_{i}$, of operating in noncorporate form. Reported taxable income can change for other reasons, however.

To begin with, income reported by noncorporate firms may well include labor as well as capital income earned by the proprietors/partners. Since the two arc treated the same for tax purposes, the presence of labor incomc does not affect the theoretical story, though it convinced us not to make use of the noncorporate income data.

In addition, corporations have some ability to shift reported income between the firm and its employees and between the firm and its shareholders, so as to reduce their combined tax payments. Loans from the party facing the low tax rate to the party facing the high tax rate would be one device that can be used for this purpose. These tax gains from income shifting were ignored in the above derivation, causing us to overestimate the size of $C_{i}$. The resulting bias to our estimate of $C_{i}$ should be larger the larger the absolute value of the difference between the corporate rate and the personal rates faced by employees and shareholders. To test for this bias, we measured the tax difference by $\Delta t \equiv \operatorname{abs}\left(\tau-\max \left(m_{b}\right)\right)$, on the assumption that corporate shareholders and top executives are primarily in the top tax bracket, and examine below its relation to our estimates of $C_{i}$.

Another source of potential bias arises from differences in the explicit tax provisions affecting corporatc vs. noncorporatc firms. Corporations, for example, face more liberal rules affecting the payment of tax-free fringe benefits to their employees. Everything else equal, this provision makes the corporate form more attractive, again creating an upward bias in our estimate of $C_{i}$.

\subsection{No-loss-offset provisions}

In the above analysis we assumed implicitly that firms would receive tax refunds if their taxable income were negative in a year. Technically, this is not allowed for any firm. Noncorporate owners, however, can use other income to offset losses, while corporations with losses can merge with 
corporations with profits. Both can carry any excess losses forward to offset income in future years. Neither strategy is equivalent to full-loss offset, however.

To the extent that a firm faces a binding restriction on the deductibility of its losses, then its marginal tax rate is zero rather than the statutory rate. Since corporations are more likely to face such binding restrictions, given that noncorporate owners can deduct losses against other income, our procedure likely underestimates the tax advantage of the noncorporate form for firms with tax losses, and therefore underestimates $C_{i}$. In years when tax losses are important, this bias should be larger. To test for this, we examine below the relation between $C_{i}$ and the fraction of capital in an industry each year owned by firms earnings tax losses, a fraction we denote by $L_{i}{ }^{45}$

\subsection{Transactions costs when firms change organizational form}

Our model of the choice of organizational form for a firm is entircly static, and so we implicitly assumed no tax or nontax costs of changing organizational form. There are clearly tax implications, however, of changing organizational form. In particular, all accrued capital gains must be realized and taxes paid on them when a firm shifts from corporate to partnership form. ${ }^{46}$ While new firms are not affected directly by these provisions, they would take into account the possible desire to change organizational forms in the future when deciding initially what form to choose. These penalties for changing organizational form should thereforc reduce the extent to which firms respond to temporary tax changes, and slow the aggregate response even to permanent changes. When the size of the noncorporate sector is increasing, this increase would be slower than we forecast, causing us to overestimate the size of $C_{i}$, and conversely when the noncorporate sector is shrinking. ${ }^{47}$ We therefore expect a positive relation between $C_{i}$ and $\Delta F_{i}$, and test for this below.

Recapture provisions and other transactions costs can also complicate the analysis for firms that face changing tax liabilities over time even if the tax law is unchanging. An example would be a firm engaged in oil exploration, with heavy drilling and development expenses for its first few years of operations, and no taxable income until recovered oil is sold on the market. Such a firm would have negative values for $\bar{Y}_{i}$ during these initials years, and

\footnotetext{
${ }^{45}$ To the extent that corporate and noncorporate firms face similar difficulties in deducting losses, our estimates of $C_{i}$ would be less systematically biased, so should be less affected by variation in the $L_{i}$.

${ }^{46}$ No such provisions apply if the corporation instead shifts to a subchapter-S corporate form.

${ }^{47}$ In principle, if these costs are larger for shifts from corporate to noncorporate form than for shifts in the reverse direction, then the former shifts should occur even more slowly.
} 
positive values later when the oil is marketed. If there were no transactions costs, then the firm would change organizational form over time, based on the size of $\bar{Y}_{i}$ at each date. In fact, this has been the practice in the oil and gas drilling sector - these firms generally start as partnerships and incorporate once their income turns positive. This behaviour is also commonly observed among new firms, which generally face tax losses during their first few years of existence and taxable profits later.

If transactions costs are important, however, then firms should consider the tax implications of their choice of organizational form over a longer time horizon. To the extent that $\bar{Y}_{i}$ or the tax law changes within this horizon, then expectations of future values affect current decisions, complicating the analysis.

\subsection{Regression results}

On the basis of the above discussion, we expect $C_{i}$ to be larger when $\Delta t$ is large (corporations then have more opportunity for tax arbitrage), when $\Delta F_{i}$ is large (due to adjustment costs, the corporate sector remains larger than it would be otherwise when the noncorporate sector is growing, implying a larger estimate of $C_{i}$ ), and when $L_{i}$ is small (corporations have more difficulty taking full advantage of tax losses). In addition, $v_{i}$ and $s_{i}$ should both have positive effects on $C_{i}$ based on the Fama-Jensen discussion. Finally, the regulatory changes discussed above lead to the forecast that $C_{i}$ should go up starting in 1976, and should drop starting in 1982. To test for this, we include two dummy variables: one that equals one from 1976 on and zero otherwise, and a second that equals one starting in 1982.

We report the resulting coefficient estimates in Table 3 . The coefficients on $\Delta F_{i}$ and $\Delta t_{i}$ have the wrong sign, but are very imprecisely estimated. All of the other coefficients have the expected signs. The coefficients of $v_{i}$ and $s_{i}$

Table 3

Estimated biases in calculation of non-tax cost of noncorporate form

Dependent variable: estimates of non-tax cost, $C_{i}$

\begin{tabular}{lclrl}
\hline Variable & Coefficient & Std. error & $t$-ratio & $P>|t|$ \\
\hline Finity/firm, $v_{t}$ & 0.0748 & 0.025 & 2.987 & 0.004 \\
Loss fraction, $L_{i}$ & -0.0346211 & 0.0722149 & -0.479 & 0.633 \\
Change in fraction noncorp., $\Delta F_{i}$ & -0.0005397 & 0.0864309 & -0.006 & 0.995 \\
Tax spread, $\Delta t$ & -0.8624618 & 0.960033 & -0.898 & 0.371 \\
Regime 2, 1976- & 0.0401619 & 0.0179313 & 2.240 & 0.027 \\
Regime 3, 1982- & -0.215307 & 0.1839948 & -1.170 & 0.245 \\
Diversifiable risk, $s_{i}$ & 1.819956 & 2.09319 & 0.869 & 0.387 \\
Intercept & 0.212557 & 0.2099582 & 1.012 & 0.314 \\
\hline
\end{tabular}

Notes: The regression has 114 observations, one for each of eight industries for each of the 16 years $1970-86$ (except 1971). The $R^{2}$ was 0.19 . 
are now larger and more significant than in the earlier regression. The dummy variables capturing regulatory changes both have coefficients that are large in magnitude, suggesting that such regulatory changes can have powerful effects on incentives. For example, while the raw mean of $C_{i}$ over time was 0.047 , the coefficients imply that the regulatory changes in 1976 increased its value by 0.04 whereas those in 1982 led to a large drop. ${ }^{48}$

While the three coefficients capturing possible biases all have the right sign, none is near to being statistically significant and none has coefficients that are large enough to be of economic interest, giving us more confidence in our estimates of $C_{i}$. Several possible sources of bias were not tested for, however.

\section{Conclusions}

The differential tax treatment of corporate and noncorporate income under existing U.S. law creates an incentive for firms with extreme taxable rates of return to become noncorporate and be owned by investors in extreme personal tax brackets. In particular, investors in high tax brackets face a tax incentive to invest in noncorporate firms generating tax losses ( $\operatorname{tax}$ shelters), so that the tax losses can be deducted against the top personal tax rates rather than against the lower corporate rate. Similarly, investors in low tax brackets have an incentive to own noncorporate firms generating substantial taxable income, so that this income is taxed at these low personal rates rather than at the higher corporate rate. The degree to which firms choose not to incorporate, to obtain these potential tax savings, depends on the size of any nontax costs (benefits) of organizing a firm in noncorporate form.

We estimated the size of nontax costs needed to reconcile the observed fraction of firms choosing the noncorporate form with the fraction that would be forecasted to do so by the theory. On average the estimated nontax costs were sizable, equaling each year roughly $3.8 \%$ of a representative firms' equity value. The size of these nontax costs varied substantially by industry, however. As forecast by Fama and Jensen (1983a,b), the nontax costs of operating in noncorporate form tended to be larger in industries where firms are riskier and where firms need to raise more capital from the market. The size of these nontax costs also varied substantially over time as would be expected given the changing regulatory treatment of corporate and noncorporate firms.

\footnotetext{
${ }^{48}$ The estimated of drop of -0.22 is in itself implausible, though insignificant. As can be seen from Table 2, the Regime 3 dummy is very highly correlated with the variable $\Delta t_{i}$, so that the coefficients of these two variables cannot be estimated reliably.
} 
In spite of the large average size of these nontax costs, the efficiency gains from removing the differential tax treatment appear to be small. The estimated efficiency gains from changes in organizational form upon shifting to a partnership tax treatment of corporate income equal only about $9 \%$ of initial business tax payments. This occurs because noncorporate firms are concentrated in industries where nontax costs appear to be low. Our estimate seems quite consistent with the very limited responsiveness of organizational form decisions to taxes found by MacKie-Mason and Gordon (1991), and is in sharp contrast to the efficiency gain of roughly $120 \%$ of tax revenue estimated by Gravelle and Kotlikoff (1989).

\section{Acknowledgements}

We are grateful to Alec Rodney, Yong Yang, and David Hummels for their diligent assistance on this project. We also wish to thank participants in seminars at the Norwegian School of Management and the Norwegian School of Economics and Business Administration, participants in the Joint University of Michigan-University of Western Ontario Theory Conference, and in the Trans-Atlantic Public Economics Seminar held in Munich during 11-13 June, 1992, two referees, and especially Dominique Demougin and Wolfram Richter, for their comments on an earlier draft, MacKie-Mason was visiting the Department of Economics, University of Oslo, while this paper was completed. Financial support for the project was provided through N.S.F. Grant No. SES 9122240.

\section{References}

Fama, E.F. and M.C. Jensen, 1983a, Separation of ownership and control, Journal of Law and Economics 26, 301-326.

Fama, E.F. and M.C. Jensen, 1983b, Agency problems and residual claims, Journal of Law and Economics 26, 327-349.

Feldstein, M.S., L. Dicks-Mireaux and J. Poterba, 1983, The effective tax rate and the pretax rate of return, Journal of Public Economics 21, 129-158.

Feldstein, M.S. and J. Slemrod, 1980, Personal taxation, portfolio choice, and the effect of the corporate income tax, Journal of Political Economy 88, 854-866.

Feldstein, M.S. and L. Summers, 1977, Is the rate of profit falling?, Brookings Papers on Economic Activity, 211-227.

Gravelle, J.G. and L.J. Kotlikoff, 1989, The incidence and efficiency costs of corporate taxation when corporate and noncorporate firms produce the same good, Journal of Political Economy 97, 749-781.

Gravelle, J.G. and L.J. Kotlikoff, 1990, Corporate tax incidence and inefficiency when corporate and noncorporate goods are close substitutes, Working Paper, Department of Economics, Boston University. 
Katz, A., 1990, The duty to read the fine print in contracts, Rand Journal of Economics, Winter, 127-152.

Kotlikoff, L.J. and D.E. Smith, 1983, Pensions in the American economy (University of Chicago Press, Chicago).

MacKie-Mason, J.K. and R.H. Gordon, 1991, Taxes and the choice of organizational form, NBER Working Paper 3781.

McLure, C.E., Jr., 1979, Must corporate income be taxed twice? (The Brookings Institution, Washington, DC).

Merton, R.C., 1980, On estimating the expected return on the market: An exploratory investigation, Journal of Financial Economics 8, 323-361. 